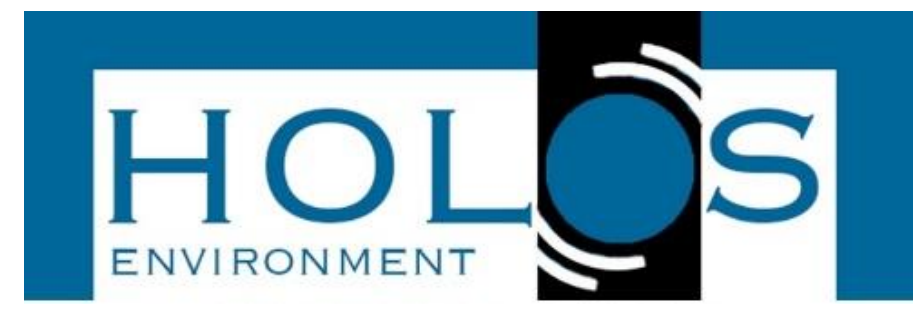

\title{
MAPEAMENTO E VERIFICAÇÃO DA EXISTÊNCIA DE SISTEMA PRÉVIO DE TRATAMENTO DE EFLUENTES NAS FONTES GERADORAS DE EFLUENTES OLEOSOS NO MUNICÍPIO DE COXIM
}

\section{MAPPING AND VERIFICATION OF THE EXISTENCE OF A PREVIOUS EFFLUENT TREATMENT SYSTEM IN THE SOURCES OF OILY EFFLUENTS IN THE MUNICIPALITY OF COXIM}

\author{
Cleiton Oliveira dos Santos ${ }^{1}$; Josenilson de Assis Ferreira ${ }^{1}$; Thiago Oliveira Bar- \\ bosa1; Paulo Martins da Silva Junior $^{1}$
}

Artigo recebido em: 01/07/2019 e aceito para publicação em: 21/11/2019.

DOI: http://dx.doi.org/10.14295/holos.v19i4.12349

\begin{abstract}
Resumo: A Política Nacional de Resíduos Sólidos determina a obrigatoriedade de aplicação da logística reversa para Óleos Lubrificantes, seus derivados e suas embalagens, devido ao risco que este produto oferece ao meio ambiente, entretanto, verifica-se o descumprimento deste dever pelos geradores. Portanto, este estudo objetivou mapear e diagnosticar a situação de empreendimentos que geram esse resíduo no município de Coxim, verificando a existência de um sistema prévio de tratamento de efluentes, o que permite sua posterior logística reversa. Neste sentido a metodologia adotada foi o mapeamento das fontes por meio de visita aos pontos e anotação das coordenadas geográficas com o auxílio de um GPS, após os dados foram processados com auxílio do software livre Quantum GIS. Foram 40 pontos potencialmente geradores de efluentes oleosos em atividade no município: são lavadoras de veículos, oficinas mecânicas, oficinas de moto e postos de combustível, dos quais cerca de $83 \%$ possuem sistemas de pré-tratamento de efluentes, que são as caixas separadoras de água e óleo. $7 \%$ apresentam seus sistemas com algum problema operacional ou de forma inadequada, a maior quantidade de empreendimentos em dissonância com a Política Nacional é a mecânica de veículos, já que os postos apresentam $100 \%$ de eficiência no tratamento anterior, pois todos possuem caixas separadora de água e óleo. Conclui-se com este trabalho que existe a necessidade da mecânica de veículos se adaptarem às políticas vigentes, como postos de gasolina, embora seja necessário aplicar sistemas de pré-tratamento para tratamento de efluentes a todos os potenciais geradores do município, a cidade de Coxim, tem valores significativamente positivos, uma vez que a grande maioria das empresas conta com esse sistema o que implica na operacionalização da logística reversa obrigatória na região de estudo.
\end{abstract}

Palavras-chave: Logística Reversa. Tratamento de efluentes. SIG. Gestão ambiental urbana.

\begin{abstract}
The National Solid Waste Policy determines the mandatory application of reverse logistics to Lubricating Oils, their derivatives and their packaging due the risk that this product offers to environment, however, it is usually verified the non-fulfillment of this duty by the generating sources of this scrap Therefore, this study aims was to map and diagnose the situation of enterprises that generate this residue in municipality of Coxim, verifying the existence of a previous effluent treatment system in them, which allows their subsequent reverse logistics. In this sense the methodology adopted for the accomplishment of this one was the mapping of the sources by means of visit to the points and annotation of the geographical coordinates of all with the aid of a GPS, later data were processed with help of free software Quantum GIS. There were 40 potentially oily effluent generating points in their activities in the
\end{abstract}

\footnotetext{
1 Universidade Estadual de Mato Grosso do Sul (UEMS), Dourados, MS. E-mails: (ceo.cleiton@bol.com.br, josenilsonaf@hotmail.com, thiago88oliveira84@gmail.com, paulinhomarir@gmail.com)
} 
municipality, they are vehicle washers, machine shop, motorcycle mechanics and fuel stations, of which about $83 \%$ have effluent pretreatment systems, which are the separator boxes of water and oil, although $7 \%$ present their systems with some operating problem or in an inadequate way, the largest amount of enterprises in dissonance with the National Policy are the automotive mechanics, since the fuel stations present $100 \%$ efficiency in the previous treatment because they all have water and oil separator boxes. It is concluded with this work that there is a need for automotive mechanics to adapt fully to current policies, such as gas stations, although it is necessary to apply pre-treatment systems for effluent treatment to all potential generators in the municipality, the Coxim city has significantly positive values, since the great majority of enterprises rely on this system which implies in operation of compulsory reverse logistics in the region of study.

Keywords: Reverse Logistics. Wastewater treatment. SIG. Urban environmental management.

\section{INTRODUÇÃO}

A Política Nacional de Resíduos Sólidos de 2010 determina em seu artigo 33ํㅡㄴ que os fabricantes, importadores, distribuidores e comerciantes de 6 produtos são obrigados a estruturar e implementar sistemas de logística reversa, entre estes figuram os óleos lubrificantes, seus resíduos e embalagens (BRASIL, 2010).

Os óleos lubrificantes, dispersos indevidamente no meio podem representar danos irreparáveis aos ecossistemas naturais. Segundo Guimarães (2015), os óleos lubrificantes podem contaminar solo e água. Oliveira (2014), comprova que tais componentes em contato com a água afetam o pH da mesma acidificando os corpos hídricos, o que pode acarretar em danos à ictiofauna. A acidificação de corpos hídricos pode resultar, de acordo com Figueiredo (2014), em prejuízo ao sistema imune de determinadas espécies, dificultando sua estabilidade e alterando a capacidade de defesa dos mesmos perante a organismos nocivos.

Além da acidificação, os óleos lubrificantes podem causar outros problemas em corpos d'água, de acordo com Oliveira (2014), a DQO: Demanda Química de Oxigênio representa um parâmetro que se eleva conforme o acréscimo de óleos e graxas nos corpos hídricos. A DQO representa a indicação do oxigênio fundamental à estabilização de matéria orgânica em um corpo receptor (MOTA, 2008) logo um alto valor da mesma representa, indiretamente perda de Oxigênio dissolvido ás trocas gasosas da ictiofauna (PEREIRA, 2017).

Outros prejuízos dos óleos lubrificantes estão diretamente ligados à operacionalidade das Estações de Tratamento de Efluentes ETE, pois podem provocar entupimento na rede, bem como aderência de partículas nos dutos implicando em complicação no escoamento do efluente e consequentemente ruptura de encanamentos, 
mau odor e retorno de efluente às residências, além de elevação dos custos de tratamento (FONSECA, 2011; PRAMPERO, 2017).

Têm-se como principais fontes geradoras desta natureza de efluente, as oficinas mecânicas de carros e motos, postos de gasolina e lavadores de carros. De acordo com a Portaria ANP № 20, (2009) os estabelecimentos que comercializam e utilizam deste, devem armazenar e dar devida destinação aos óleos lubrificantes, sem que ocorra contaminação ao meio ambiente, sendo de total responsabilidade do empreendedor o manejo e descarte deste resíduo. Além de se imprescindível licenciamento a estes empreendimentos.

De acordo com a resolução CONAMA 362/2005:

Art. 1으o Todo óleo lubrificante usado ou contaminado deverá ser recolhido, coletado e ter destinação final, de modo que não afete negativamente o meio ambiente e propicie a máxima recuperação dos constituintes nele contidos, na forma prevista nesta Resolução.

Perante tais constatações, o presente artigo tem por objetivo levantar e mapear as fontes geradoras desta natureza de resíduos líquidos no município de Coxim-MS, bem como destacar aqueles que possuem sistema de tratamento de efluentes específico para esta natureza e os que não possuem.

\section{METODOLOGIA}

\section{1 Área de Estudo}

A área selecionada para este estudo é a cidade de Coxim que possui, de acordo com o IBGE (2018), aproximadamente 33 mil habitantes e economia predominantemente sustentada por atividades pecuárias, sua localização está disposta na Figura 1.

O município de Coxim possui $6.411,55 \mathrm{Km}^{2}$ (MS, 2009) e estratégica localização geográfica por pertencer a Região Hidrográfica do Paraguai e contribuir, por meio dos seus corpos hídricos com um importante Bioma Nacional, Reserva da Biosfera legitimada pela UNESCO: Pantanal. A vegetação local contém fragmentos de Cerradão, Veredas, Campos e demais fitofisionomias típicas do Cerrado (MS, 2014). O clima local é tropical e se caracteriza pela pouca variação nas médias diárias, chegando aos meses quentes a temperaturas máximas de $39^{\circ} \mathrm{C}$ e mínimas de $26^{\circ} \mathrm{C}$ (MS, 2009). 
Figura 1- Mapa de localização do município de Coxim, MS, BR, 2018.

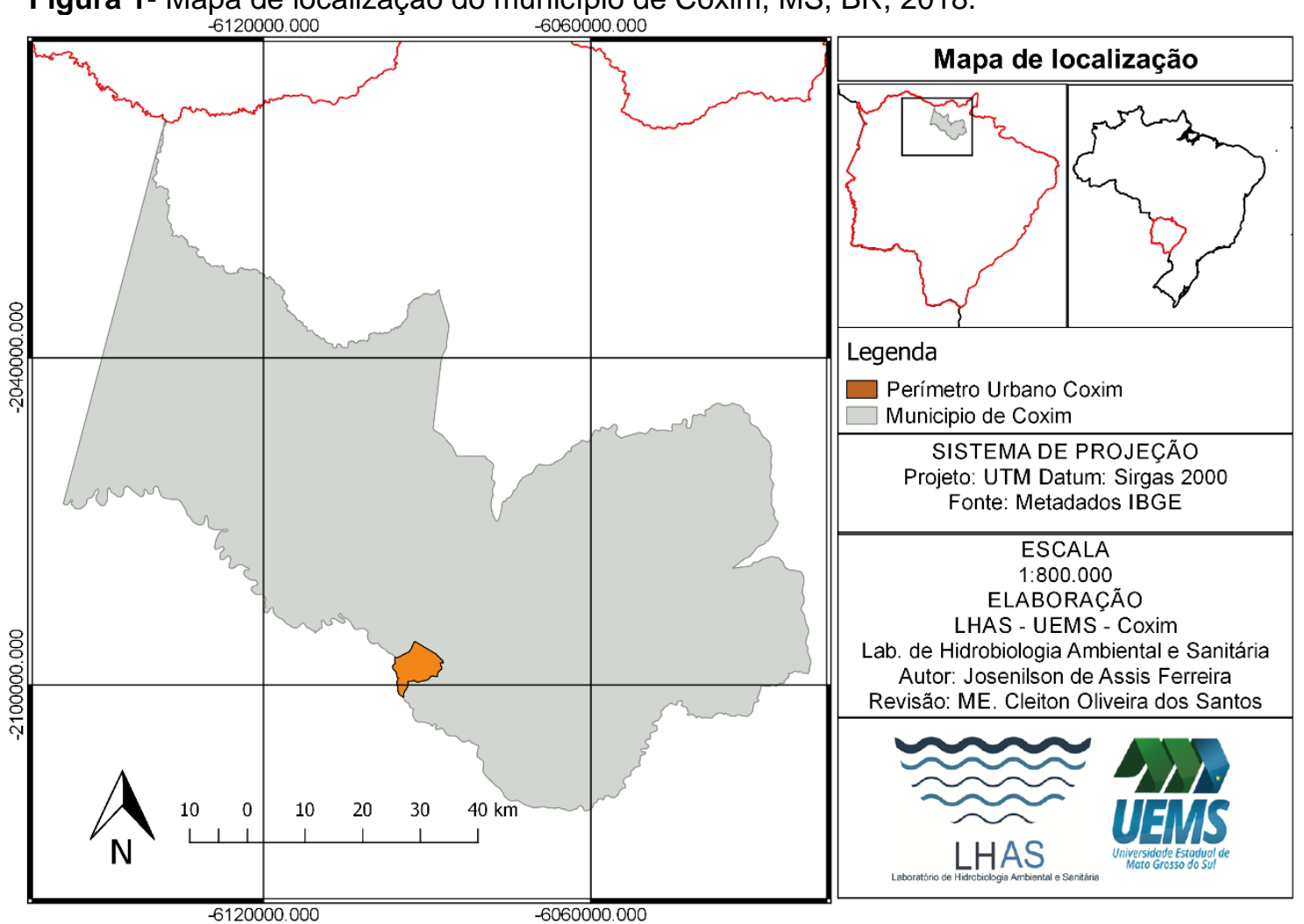

\subsection{Delimitação do universo da pesquisa}

A pesquisa em questão possui caráter quantitativo e exploratório, constitui-se de um ensaio de campo que visa, sobretudo levantar dentro do município de Coxim os empreendimentos geradores de efluentes oleosos, àqueles que possuem e que não possuem sistema de tratamento de efluentes próprio para esta natureza de resíduo líquido, a fim de fazer o mapeamento dos mesmos.

\subsection{Coleta de dados e processos analíticos}

Os dados foram coletados em campo, através de visitas a todos os empreendimentos municipais que se encaixam dentro da percepção dos autores acerca do potencial gerador desta natureza de efluente dentro dos $19 \mathrm{~km}^{2}$ de perímetro urbano do município. Os autores classificaram como alvo da pesquisa: Postos de gasolina, Oficinas mecânicas de carros e motocicletas e Lavadores de veículos.

Após a delimitação do alvo das visitas, as mesmas foram realizadas entre os dias 02 de julho de 2018 e 20 de julho de 2018, foram percorridos todos os bairros 
municipais em busca de empreendimentos geradores de efluentes oleosos e quando encontrados, os empreendedores foram perguntados se obtinham sistema de tratamento para o efluente oleoso, a partir de uma negativa apenas marcava-se as coordenadas geográficas do local com auxílio de um GPS, já quando houvesse resposta positiva os autores pediam para visualizar este sistema e em seguida marcavam a coordenada geográfica com auxílio de um GPS.

Em todas as visitas, a localização geográfica foi coletada por meio de um GPS localizador, a fim de se construir mapas interativos com todos os pontos visitados. Para a confecção dos mapas, contou-se com o auxílio do software Quantum Gis, versão 2.18.12 (QGIS, 2018), onde foram processados os dados de divisões políticas dos Estados e dos municípios de Mato Grosso do Sul, disponíveis na plataforma de metadados do Instituto Brasileiro de Geografia e Estatística - IBGE (2018).

\section{RESULTADOS}

\subsection{Empreendimentos geradores de efluentes oleosos no município de Coxim}

No município de Coxim foram encontrados 40 empreendimentos que geram em suas atividades efluentes de origem oleosa, conforme disposto na Figura 2.

Dentre estes empreendimentos, aproximadamente 17\% não contam com sistema prévio de tratamento de efluentes, estes se encontram em discordância com as políticas regulatórias vigentes neste âmbito, porém a grande maioria cerca de $83 \%$ dos empreendimentos contam com caixas separadoras de água e óleo, que representam o sistema prévio adequado para o tratamento de efluentes oleosos, a Figura 3 dispõe o quantitativo de empreendimentos que possuem sistema prévio de tratamento. 
Figura 2 - Mapa de localização dos empreendimentos geradores de efluentes oleosos no perímetro urbano de Coxim/MS

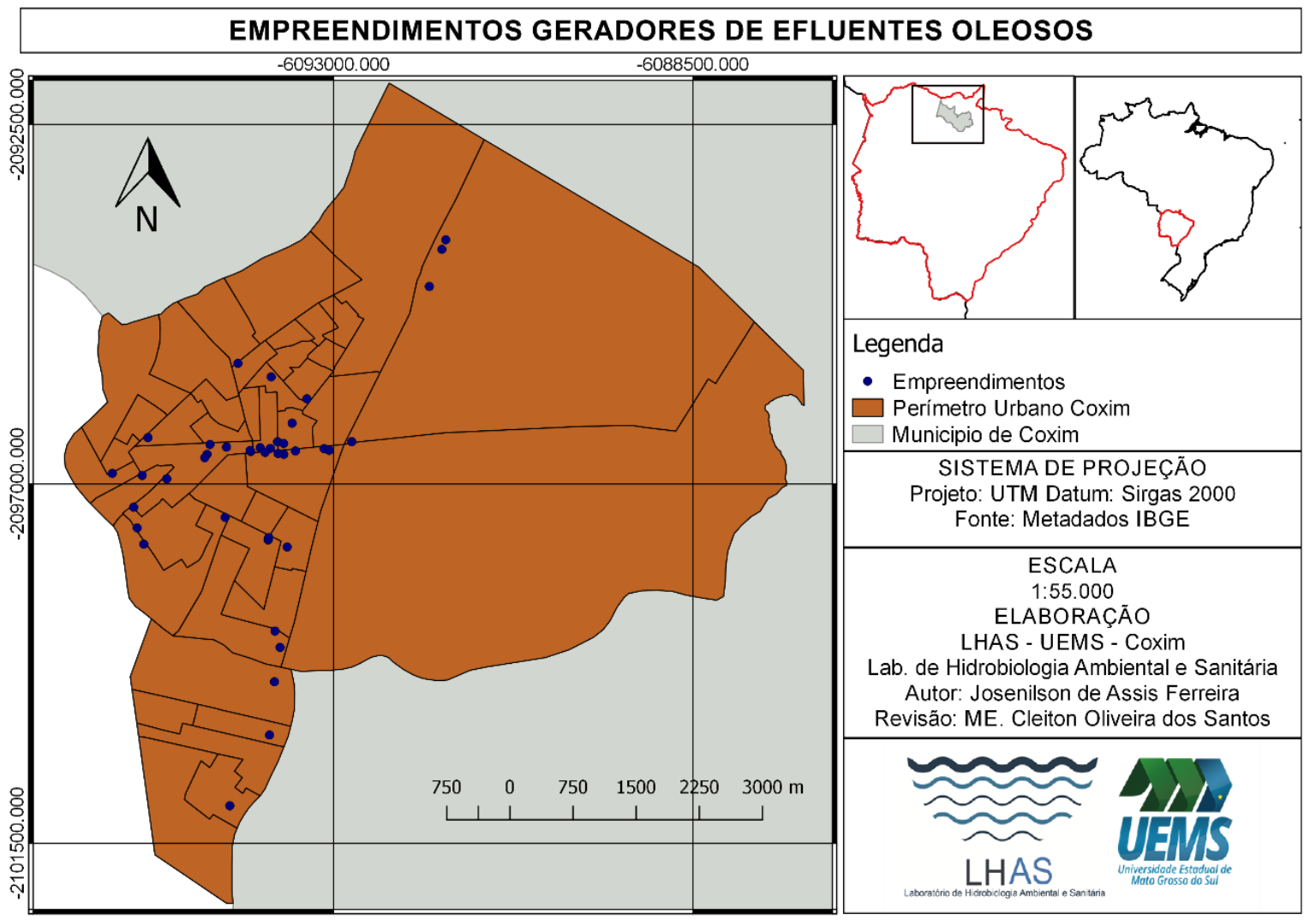

Figura 3 - Sistema prévio de tratamento de efluente nos empreendimentos de Coxim

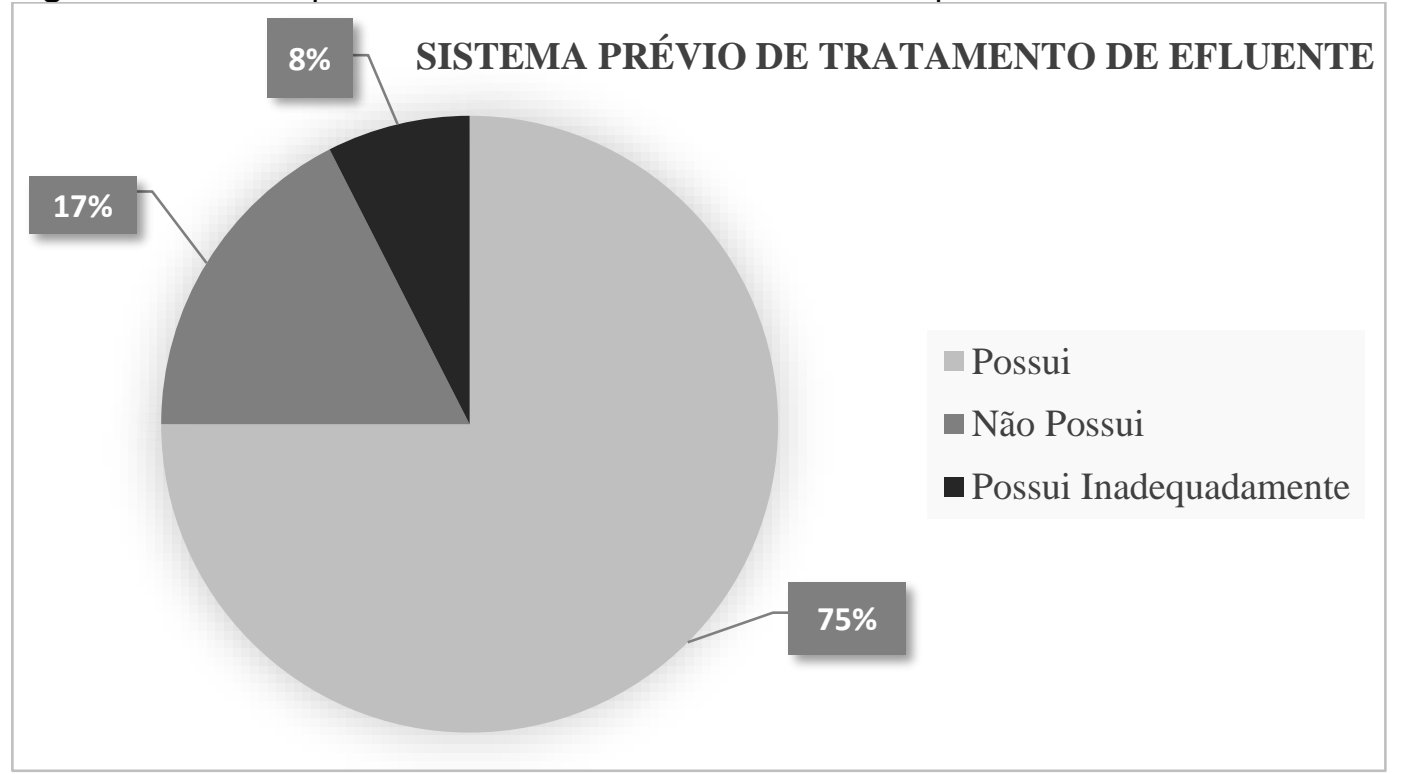

Fonte: Elaboração própria

Perante o que foi visualizado em campo cerca de $83 \%$ das fontes geradoras contam com sistemas prévios de tratamento de efluentes oleosos, embora $8 \%$ destes contem com sistemas inadequados como os próprios empreendedores informaram, a 
localização destes empreendimentos de acordo com a presença e ausência de sistema prévio de tratamento de efluentes oleosos está disposta na Figura 4.

Figura 4 - Disponibilidade de sistema prévio de tratamento de efluente nos empreendimentos

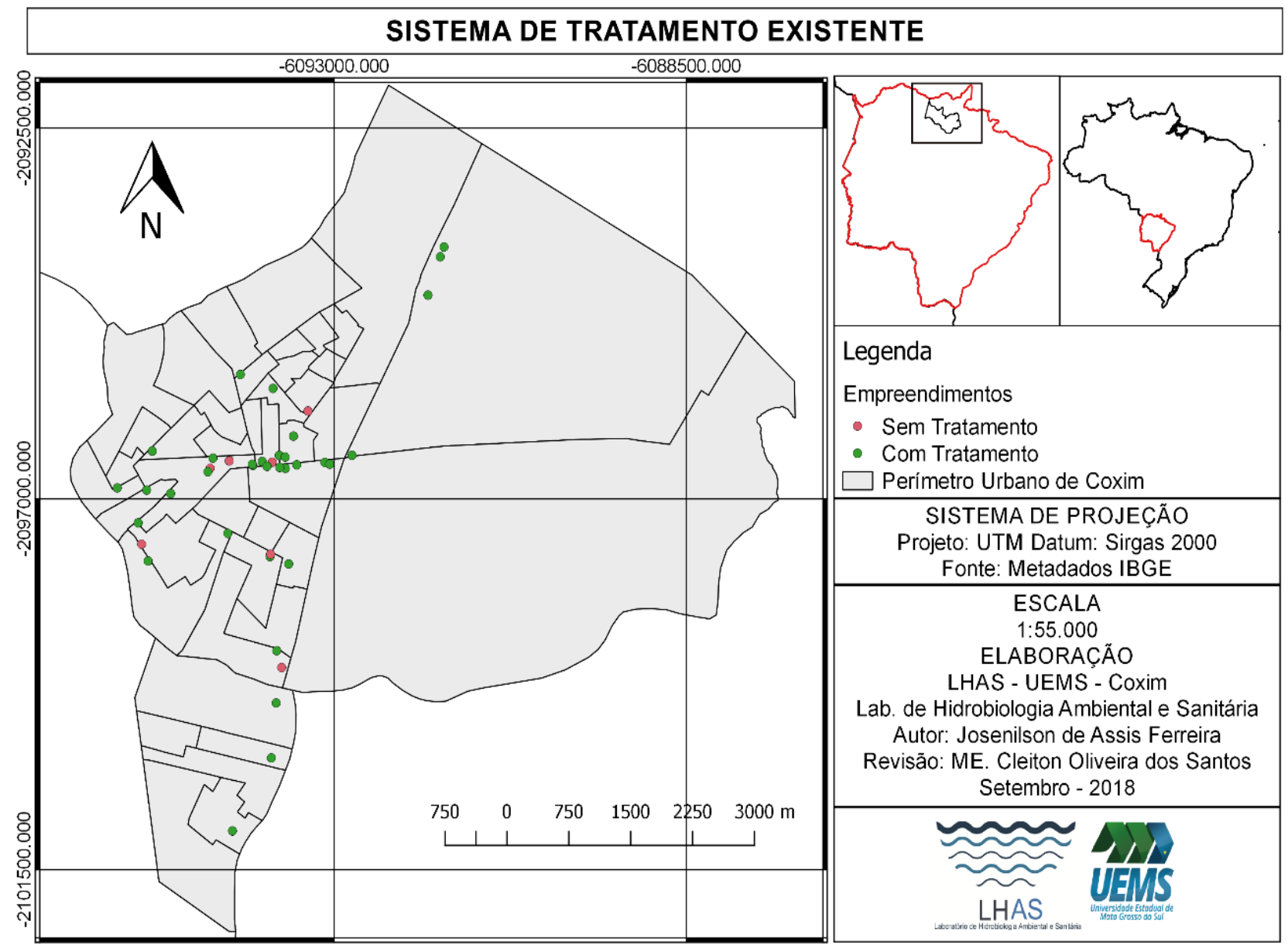

É possível ainda separar os empreendimentos de acordo com a atividade exercida pelos mesmos, identificou-se no município de Coxim quatro tipos de empreendimentos geradores de efluentes oleosos, Lavadores automotivos, Mecânicas de veículos automotores, mecânicas de motocicletas e Postos de Gasolina, que se dispersam conforme representa a Figura 5.

É possível inferir que as mecânicas de veículos representam o maior montante deste segmento de empreendimentos, identificou-se ainda por atividade àqueles que possuem ou não sistema de tratamento prévio para o tratamento do efluente oleoso conforme representa a Figura 6 . 
Figura 5 - Tipos de empreendimentos geradores de efluentes oleosos no perímetro urbano de Coxim

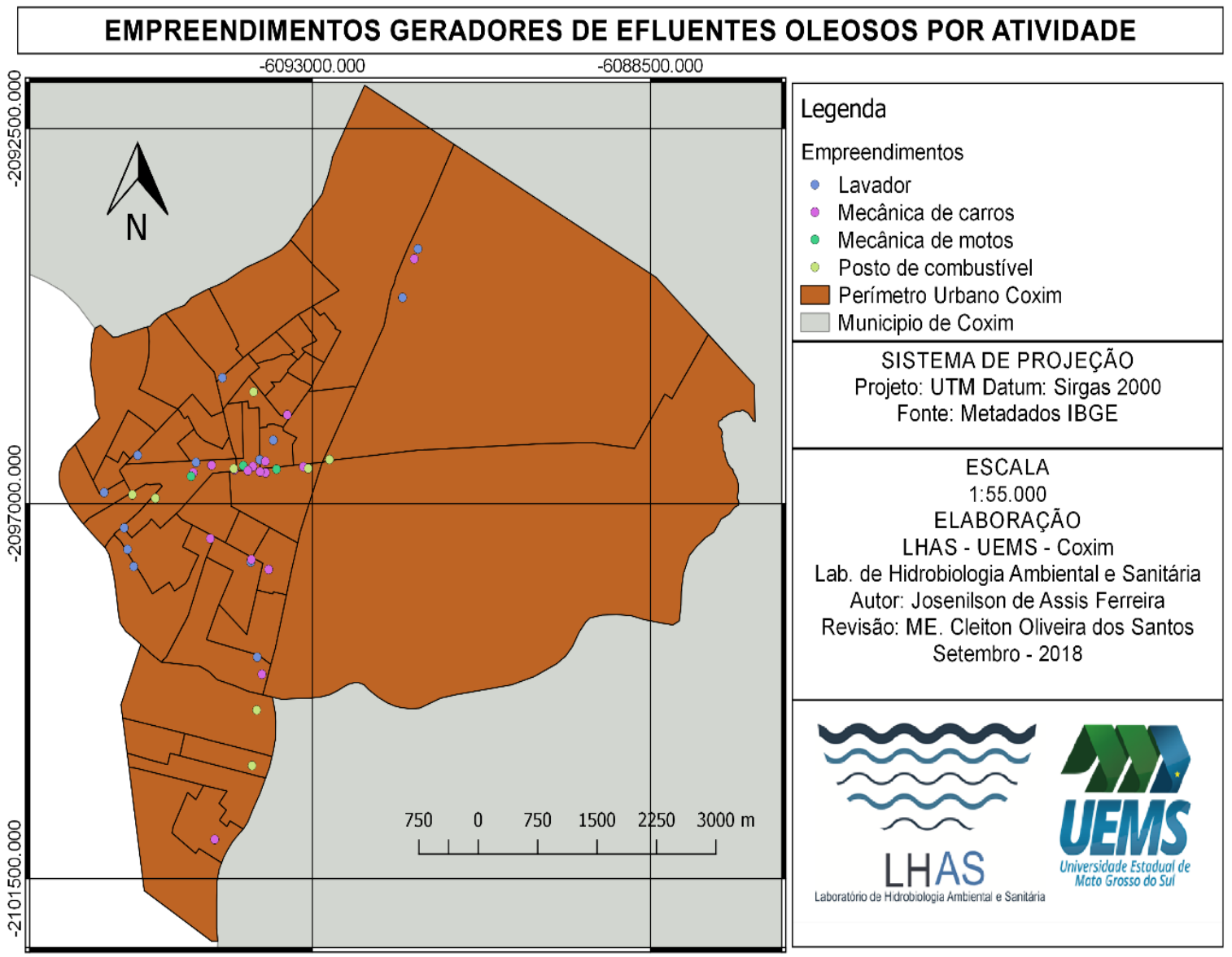

Figura 6 - Disponibilidade de sistema prévio de tratamento de efluentes por atividade

\section{DISPONIBILIDADE DE SISTEMA PRÉVIO DE TRATAMENTO DE EFLUENTES}

12

8

6

4

2

0

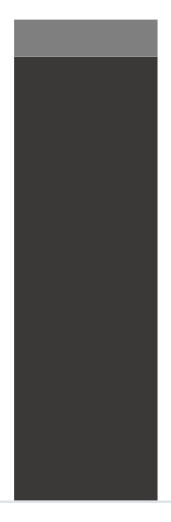

Lava-jato

Mecânica de motch
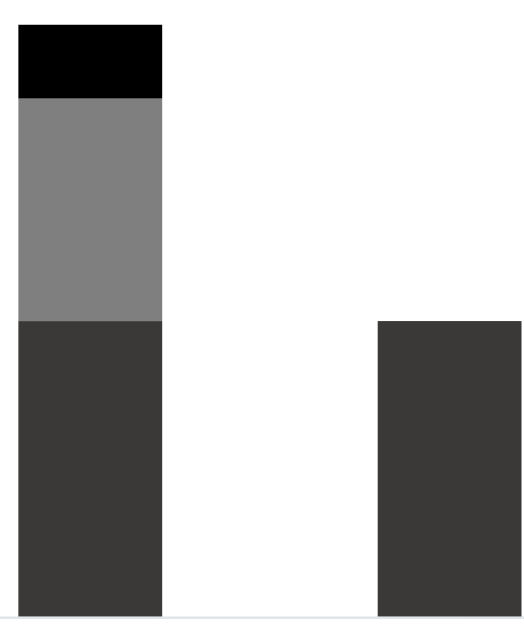

- Possui - Não Possui - Possui Inadequadamente

Fonte: Elaboração própria 
É possível inferir que os postos de gasolina quando analisados apresentam $100 \%$ de eficiência, a esta constatação atribui-se o fato de a política para estas organizações serem mais rigorosa, alguns apresentam o sistema, mas de forma inadequada conforme os empreendedores relataram por se tratarem de instalações antigas e/ou por não serem utilizadas.

\subsection{Discussão dos Resultados}

O recolhimento do óleo lubrificante nos empreendimentos para posterior logística reversa no município de Coxim se faz de maneira satisfatória quando comparado com ensaios semelhantes, Miranda Filho (2013) em um diagnóstico das oficinas mecânicas de uma cidade mineira verificou que apenas 33\% destas apresentavam o sistema prévio de tratamento, Paulino (2009) levantou que em apenas $47 \%$ das oficinas mecânicas de uma cidade do interior de São Paulo é realizado o tratamento prévio deste efluente.

Em um estudo realizado por Tsambe (2017) constatou-se que o Brasil produz anualmente um montante de 1,8 Bilhões de litros de óleo lubrificante, destes, aproximadamente $21 \%$ possuem destino incerto. O município de Coxim, de acordo com o que foi constatado, fica abaixo desta média nacional pois $83 \%$ dos empreendimentos apresentam sistema de tratamento prévio o que facilita o processo de logística reversa deste resíduo perigoso, porém não se tem a certeza acerca da destinação final dos efluentes, o trabalho constatou apenas a presença e/ou ausência dos sistemas de tratamento prévio.

A falta de sistema prévio de tratamento para o efluente oleoso, acontece pela falta de fiscalização dos órgãos ambientais como observou Paulino (2009) em seu estudo, cerca de $70 \%$ dos empreendimentos analisados responderam não existir alguma fiscalização para suas atividades no que tange à qualidade ambiental.

\section{CONCLUSÃO}

Diante das constatações feitas, observa-se uma necessidade de as mecânicas automotivas se adequarem de maneira integral às políticas vigentes, a exemplo dos postos de gasolina que em $100 \%$ apresentam sistema prévio de tratamento de efluente. Um fator agravante aos empreendimentos que não apresentam caixa 
separadora de água e óleo no cenário de Coxim é que existem corpos d'água muito próximos do perímetro urbano e uma contaminação destes significa risco à estabilidade do bioma Pantanal.

A Política Nacional de Resíduos Sólidos deixa bem claro a obrigatoriedade dos empreendimentos em aplicar a logística reversa aos Óleos Lubrificantes porém observa-se comumente a falta de sistemas que venham a contribuir para que esta seja desenvolvida com excelência, o município de Coxim apresenta mais de $80 \%$ de empreendimentos contando com caixas separadoras, embora alguns destes obtenham as mesmas em condições inadequadas, este resultado presenta um padrão de qualidade melhor que a média nacional, que é consideravelmente eficiente, logo entendese que os valores apresentados no trabalho revelam um dado positivo.

Conclui-se com o presente artigo que, embora seja necessário aplicar sistemas de tratamento prévio de tratamento de efluentes a todos os potenciais geradores do município, a cidade de Coxim apresenta valores significativamente positivos, pois a grande maioria dos empreendimentos conta com este sistema o que implica no funcionamento da logística reversa obrigatória na região de estudo, porém a fiscalização ambiental deve ser executada com maior frequência e discernimento para que os demais se enquadrem nas políticas existentes.

\section{REFERÊNCIAS}

AGÊNCIA NACIONAL DO PETRÓLEO. Portaria nำ20. Dispõe sobre os requisitos necessários à autorização para o exercício da atividade de coleta de óleo lubrificante usado ou contaminado e a sua regulação. Diário Oficial [da] República Federativa do Brasil, Brasília, DF, 19 jun. 2009. Disponível em: https://www.legisweb.com.br/legislacao/?id=111856. Acesso em 24 jun. 2018.

BRASIL, Lei no 12.305 de 02 de agosto de 2010. Institui a Política Nacional de Resíd uos Sólidos; altera a Lei no 9.605, de 12 de fevereiro de 1998; e dá outras providências. Diário Oficial [da] República Federativa do Brasil, Brasília, DF, 03 Ago. 2010. Disponível em: http://www.planalto.gov.br/ccivil 03/ ato2007-2010/2010/lei/l12305.htm. Acesso em: 16 jul. 2018.

CONAMA Resolução 362. Dispõe sobre o recolhimento, coleta e destinação final de óleo lubrificante usado ou contaminado. Diário Oficial [da] República Federativa do Brasil, Brasília, DF, 27 jun. 2005. Disponível em: http://www.mma.gov.br/port/conama/legiabre.cfm?codlegi=466. Acesso em: 25 jun. 2018.

FIGUEIREDO, Débora Alvares Leite. Efeito da acidificação da água do mar no sistema imune e no balanço ácido-base de ouriços-do-mar Lytechinus variegatus (Lamarck, 
1816) e Echinometra lucunter (Linnaeus, 1758). Tese de Doutorado. Universidade de São Paulo.

FONSECA, Sandra Parreiras Pereira; De AZEVEDO, Sirlei Geraldo; ABREU, Luciano Ferreira; Da SILVA, Diego Henrique Carvalho; Da MOTA, Vandeir Geraldo. II-447-Impactos gerados em uma lagoa facultativa pelo derramamento clandestino de óleos e graxas (estudo de caso).

GUIMARÃES, Tainá Thomassim; TOMBINI, Melina Cé; FERRO, Matheus Pielechovski; KIELING, Amanda Gonçalves; \& MORAES, Carlos Alberto Mendes. Avaliação de aspectos e impactos ambientais: estudo de caso em uma indústria gráfica. In: FORUM INTERNACIONAL DE RESÍDUOS SÓLIDOS, 2015. [Anais...], 2015.

INSTITUTO BRASILEIRO DE ESTATÍSTICA E GEOGRAFIA. (IBGE). Dados de divisão política dos Municípios e Estados do Brasil. IBGE. 2018. Disponível: em: https://www.ibge.gov.br/geociencias-novoportal/organizacao-do-territorio/divisao-regional/15778-divisoes-regionais-do-brasil.html?=\&t=0-que-e. Acesso em: 22 jul. 2018.

MATO GROSSO DO SUL (Estado). Lei oㅜ 3.839, de 28 de dezembro de 2009. Zoneamento Ecológico Econômico do Estado de Mato Grosso do Sul. Diário Oficial do Estado, Campo Grande, 29 Dez. 2009. Disponível em: http://193.43.36.109/docs/pdf/bra116233Annexl.pdf. Acesso em 22 jul. 2018.

MATO GROSSO DO SUL (Estado). Plano de Manejo Rio Cênico das Rotas Monçoeiras. Diário Oficial do Estado, Campo Grande, 10 Out. 2014. Disponível em: http://www.imasul.ms.gov.br/wp-content/uploads/sites/74/2015/06/APA-Rio-C\%C3\%AAnico-PlanoExecutivo.pdf. Acesso em 22 jul. 2018.

MIRANDA FILHO, Roberto; FERREIRA, Quênia Cândida; RIBEIRO, Fabrício Alves. Avaliação ambiental das oficinas mecânicas que realizam troca de óleo na cidade de monte Carmelo-MG. Revista GeTeC, v. 1, n. 1, 2013.

MOTA, S. Conservação e preservação de recursos hídricos. 2. ed. rev. Atual. Rio de Janeiro: ABES, 2008.

OLIVEIRA, Jairo Pinto; ANTUNES, Paulo Wagnner Pereira; PINOTTI, Laura Marina; \& CASSINI, Sérvio Túlio Alves. Caracterização físico-química de resíduos oleosos do saneamento e dos óleos e graxas extraídos visando a conversão em biocombustíveis. Química Nova, v. 37, n. 4, p. 597-602, 2014.

PAULINO, Paloma Fernandes. Diagnóstico dos resíduos gerados nas oficinas mecânicas de veículos automotivos do município de São Carlos-SP, 2009.

PEREIRA, Samanta Vieira; MACHADO, Priscilla Rocha; SILVA, Nátaly de Sousa Ferreira Cruz. Análise da qualidade da água do rio arroio fundo-RJ após a construção de uma estação de tratamento de água de rio, 2017.

PRAMPERO, Julio Cesar. Fatores operacionais na manutenção da eficiência de um reator UASB compartimentado tratando esgoto sanitário, 2017.

QUANTUM GEOGRAPHIC INFORMATION SYSTEM (Qgis). Software livre que permite a visualização, edição e análise de dados georreferenciados. Fundação Geoespacial de Código Aberto. Versão 2.18.12, 2018. 
TSAMBE, Malaquias Zildo António; DE ALMEIDA, Cássio Florisbal; LOHMANN, Gabriele; SANTIAGO, Mariana Ribeiro; \& DE ABREU CYBIS, Luiz Fernado. Avaliação do sistema de gerenciamento de óleos lubrificantes usados ou contaminados no Brasil. Tecno-Lógica, v. 21, n. 2, p. 75-79, 2017. 